\title{
The best on infections: update from the 2010 ERS Congress
}

\author{
M. Miravitlles, G. Sotgiu, G. Dimopoulos, G. Rohde, R. Centis, G. Ferrara, S. Ewig, \\ F. Blasi and G.B. Migliori
}

\begin{abstract}
Respiratory tract infections and tuberculosis are among the leading reasons for seeking medical care. In this report the most recent advances in the field of clinical research and basic sciences of respiratory infections and tuberculosis are presented through the analysis of some of the best abstracts presented at the 20th European Respiratory Society Congress in Barcelona, Spain and their subsequent publications in major journals. The role of viruses in chronic obstructive pulmonary disease exacerbations, the importance of new biomarkers in the management and risk assessment of lower respiratory tract infections, new modalities of treatment of respiratory infections as well as new tools for the diagnosis of latent and active tuberculosis in special subgroups of patients (children and immunocompromised individuals), and the new epidemiological threat of multidrug-resistant and extensively drug-resistant tuberculosis cases are discussed.
\end{abstract}

\section{KEYWORDS: European Respiratory Society Congress, respiratory infections, tuberculosis}

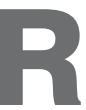
espiratory tract infections, both of viral and bacterial origin, are major causes of morbidity and mortality in the European Union (EU) [1, 2]. Tuberculosis (TB) is still one the main public health priorities both at the European and global level [3, 4].

TB sustained by multidrug-resistant (MDR) strains (resistant at least to the two most potent TB drugs, isonizid and rifampicin) and extensively drugresistant (XDR) TB strains (in which additional resistance to a quinolone plus a second-line injectable, amikacin, capreomycin or kanamycin, is detected) represents a real threat to TB control $[5,6]$. While being actively involved in international cross-cutting initiatives (TB day, World Health Day, Year of the Lung, HERMES project) [6-9], the European Respiratory Society (ERS) Respiratory Infection Assembly actively supports research and educational initiatives in these areas, being at the same time active partner in EU-funded projects within the 6th and 7th Framework Programmes, e.g. the GRACE (Genomics to combat Resistance against Antibiotics in Communityacquired LRTI in Europe) network of excellence [10] and the PAN-NET on tuberculosis [11].

This manuscript reviews some of the best contributions discussed at the 20th ERS Congress in
Barcelona, Spain by members of the Respiratory Infections Assembly, and the main publications then derived from these discussions.

\section{TUBERCULOSIS}

TB was high in the agenda of the conference, with 27 thematic sessions, one postgraduate course, four e-communication sessions, five oral sessions, five symposia/grand rounds and 12 thematic poster sessions. ERS peer-reviewed 495 abstracts on $\mathrm{TB}$, and $350(70 \%)$ of them were accepted for presentation in Barcelona.

Several hot TB topics were debated, ranging from epidemiology and clinical management of TB and MDR/XDR-TB in healthy and special (HIV seropositive individuals, immunocompromised patients, children and migrants, etc.) populations to new insights related to bacteriological and immunological diagnosis.

\section{MDR-/XDR-TB: EPIDEMIOLOGICAL AND CLINICAL IMPLICATIONS}

Important news on MDR- and XDR-TB has been presented from different settings and perspectives.

TB control in large European cities has been discussed by two scientific groups working in the UK. STORY et al. [12] found that TB incidence is increasing in London with 3,500 cases reported in

\section{AFFILIATIONS}

For a list of the authors' affiliations, see the Acknowledgements section.

CORRESPONDENCE

G.B. Migliori

WHO Collaborating Centre for Tuberculosis and Lung Diseases,

Fondazione S. Maugeri

Care and Research Institute

Via Roncaccio 16

21049 Tradate

Italy

E-mail: giovannibattista.migliori@

fsm.it

Received:

March 042011

Accepted after revision:

March 082011

First published online:

March 242011 
2009, of which one in six TB patients is homeless, a drug/ alcohol abuser or a prisoner. The study demonstrates that a multidisciplinary approach, involving different stakeholders and coordinated by a specialised team (the so-called "Find and Treat experience"'), is able to increase case-finding from $44 \%$ to $75 \%$ and reduce default from $50 \%$ to $5 \%$.

KRUIJSHAAR et al. [13] compared TB epidemiology in London with that in six other UK metropolitan counties between 2000 and 2008, finding that the TB incidence in London was significantly higher than in large conurbations (46 versus 20 per 100,000 population, respectively); the identification of risk groups like young black Africans suggested the need for a strengthened strategy at the national level.

ANDERSON et al. [14] from the Health Protection Agency in London evaluated treatment outcomes and their predictors in MDR-TB patients after 2 yrs. The treatment completion rate $(65.5 \%)$ is far below World Health Organization (WHO) targets, due, mainly, to poor adherence and to comorbidities.

Relevant studies from former Soviet Union countries have been presented. Among them, MisHUSTIN et al. [15] from Tomsk Oblast, Russia demonstrated that the classical epidemiological indicators (incidence, prevalence and mortality) improved following the implementation of a sound TB control programme. Similarly, treatment success rates among MDR-TB cases increased from $54.9 \%$ to $75.5 \%$.

CRUDU et al. [16] presented national trends on TB and MDR-TB epidemiology from Moldova, where an alarming increase in any primary resistance was observed associated with the increases in the prevalence of MDR-TB (from $0.5 \%$ to $22.1 \%$ between 1995 and 2009).

A second contribution from the same country described the results obtained after implementing the GenoType MTBDR plus assay to detect rifampicin and isoniazid resistance directly on smear-positive sputum specimens [17], allowing faster diagnosis and targeted treatment of MDR-TB cases in specialised centres.

TBNET and the European Centre for Disease Prevention and Control (ECDC) developed a standardised tool to survey possible mismanagement of TB and MDR-TB in European TB reference centres.

SotGIU et al. [18] described the methodology adopted for developing the survey tool and the results of its pre-test, while FACCHINI et al. [19] described the main findings of the clinical survey.

The tool study [18] was recently published [20], together with the key results of the infection control components of the survey [21].

Overall, the survey showed that drugs in anti-TB regimens, treatment duration, dosages and TB/HIV co-infection management were not in accordance to WHO recommendations in $>10 \%$ of the cases [18-20], while environmental and administrative infection control measures (e.g. use of respirators, isolation of infectious cases in negative pressure ventilation rooms) were frequently inadequate [21].
In Romania, one of the hot spots in Europe, only a minority of the HIV co-infected patients (38.9\%) was sputum smear positive, $3.8 \%$ of the cases harbouring MDR-TB strains. The treatment success rate was as low as $58.6 \%$, while $21 \%$ of them died and $6.4 \%$ defaulted [22].

SHEAN et al. [23] identified predictors of poor treatment outcome in the South African cohort of 115 XDR-TB patients, followed-up from 2002 to 2008, including adverse events (43\% of those experiencing adverse events necessitated drug discontinuation and changes in the regimens, $16 \%$ interrupted their treatment and $3.7 \%$ died).

\section{THE ROLE OF IGRAS: A CLINICAL AND PUBLIC HEALTH PERSPECTIVE}

Two important reports, aimed at solving some of the questions presently under debate on the diagnostic accuracy of interferon- $\gamma$ release assays (IGRAs), were presented (and recently published) by SESTER and Co-workers [24, 25] and by DIEL and co-workers $[26,27]$, who described the findings of two systematic reviews and meta-analyses jointly carried out by TBNET and the ECDC.

The first study summarised the scientific evidence from 27 studies, showing that IGRA tests, performed on peripheral blood specimens, are of limited value to distinguish latent TB infection (LTBI) from active TB $[24,25]$. In blood and extrasanguinous fluids, the pooled sensitivity was $80 \%$ and $48 \%$ for the QFT-G-IT test, and $81 \%$ and $88 \%$ for T-SPOT.TB test, respectively. In blood and extrasanguinous fluids, the pooled specificity was $79 \%$ and $82 \%$ for QFT-G-IT, and $59 \%$ and $82 \%$ for T-SPOT.TB, respectively.

DIEL and co-workers [26, 27] performed a systematic review and meta-analysis to compare the accuracy of the T-SPOT.TB and the QFT-G-IT tests with the tuberculin skin test (TST) to confirm or exclude LTBI. The IGRAs' specificity ranged from $98 \%$ to $100 \%$. Among IGRA-negative adults, only a small proportion developed TB after a follow-up of 2 yrs (negative predictive value for progression: $97.8 \%$ for T-SPOT.TB and 99.8\% for QFT-G-IT), while among IGRA-positive individuals this proportion ranged between $8 \%$ and $15 \%$, significantly higher than the $2-3 \%$ among TST positives. These findings, based on 53 published studies, show that IGRAs may present operational advantages compared with the TST in identifying latently infected individuals, although questions still remain about their accuracy for risk groups such as children and immunocompromised patients.

These points are also addressed in other studies presented at the ERS Congress: SESTER et al. [28] evaluated the diagnostic accuracy of the TST, T.SPOT.TB and QFT-G-IT tests in a cohort of immunocompromised patients including $652 \mathrm{HIV}$-positive and 262 chronic renal failure cases. In HIV-positive individuals with $<200 \mathrm{CD} 4+\mathrm{T}$-cells per $\mu \mathrm{L}$, the proportion of positive tests was higher for both IGRA tests than for the TST $(6.6 \% ; p=0.008)$. Higher statistically significant proportions of positive results, not associated with different $M$. tuberculosis exposure, were detected in individuals affected by chronic renal failure if compared with those in HIV-infected patients. In both immunocompromised populations, the agreement between IGRAs was moderate $(k>0.5)$, while it was fair $(\mathrm{k}>0.2)$ between IGRA and TST. 
RUHWALD et al. [29] analysed the effect of corticosteroids treatment on QFT-G-IT in 265 patients with inflammatory bowel and rheumatological diseases and the diagnostic agreement between QFT-G-IT and TST. A significant lower in vitro interferon- $\gamma$ response was found in immunocompromised individuals owing to corticosteroid therapy as well as a higher probability of indeterminate IGRA results (adjusted odds ratio 8.7; $\mathrm{p}<0.05$ ) when compared with patients not treated with corticosteroids. Concordance between QFT-G-IT and TST positivity was poor.

Similar findings were observed in a cohort from Timisoara, Romania, where the proportion of positive TST results was significantly higher among immunocompetent than in immunocompromised individuals $(27.7 \%$ versus $10.3 \%$; $=0.001)$, while no significant difference in positive results was obtained using the QFT-G-IT test between the two cohorts $(25.8 \%$ versus $23.4 \%$, respectively). Indeterminate QFT-G-IT tests were more frequently observed among immunocompromised individuals ( $20.7 \%$ versus $5.5 \%$; $=0.021)$ [30].

A UK survey on the use of IGRAs to diagnose LTBI in HIVseropositive patients demonstrated that the majority of the surveyed centres $(63 \%)$ used these novel tests, although their application in this cohort of immunocompromised individuals is not totally supported in the present National Institute for Health and Clinical Excellence guidelines [31]. One of the main findings of this study was that the majority of the clinical settings surveyed do not utilise IGRAs in TST positive subjects $(42 \%)$, highlighting how their use is contemplated mostly in subjects for whom a false-negative TST is suspected [31].

On the public health side, several studies, performed in Germany [32], Portugal [33] and India [34], assessed the serial use of IGRAs in healthcare workers.

In Germany the conversion/reversion rates of 287 healthcare workers was studied in 14 hospitals by serial testing of QFT-GIT [32]. Using an uncertainty zone around the cut-off point $\left(0.2-0.7 \mathrm{UI} \cdot \mathrm{mL}^{-1}\right)$ the discrimination between unspecific variation around the diagnostic cut-off and true conversion or reversion improved [32].

In Portugal, as demonstrated on 922 healthcare workers, the use of an uncertainty zone of $0.2-0.7 \mathrm{UI} \cdot \mathrm{mL}^{-1}$ in the range of QFT-G-IT responses might be helpful for some individuals who need further tests before LTBI treatment can be recommended [33].

An interesting study from India and Canada reported rates of conversion/reversion of QFT-G-IT in nursing trainees $(n=261)$ and the potential risk variables associated with conversion [34]. However, no statistical association between exposure and QFT-G-IT conversion rate was observed [34].

Finally, a study from Singapore demonstrated that LTBI treatment has no influence on the T-SPOT.TB positivity during the first 2 yrs following beyond exposure to a TB index case. Reversion of IGRA positivity took place in $51 \%$ among treated versus $58 \%$ among untreated contacts, with no significant difference $(p=0.39)$ [35].

\section{RESPIRATORY INFECTIONS}

The number of submitted abstracts to the ERS Congress in 2010 in the respiratory infections group (group 10.1) increased by
$18 \%$ from 2009, reaching a total of 331 submissions, of which $252(76 \%)$ were accepted. Respiratory infection was the topic of two postgraduate courses, three grand round/symposia, three oral presentation sessions, three e-poster sessions and nine thematic poster sessions. The topics covered the whole spectrum of respiratory infections, including pneumonia bronchiectasis and acute exacerbations of chronic obstructive pulmonary disease (COPD), along with aspects related to diagnosis, assessment of severity and management.

\section{RISK FACTORS AND OUTCOMES IN PATIENTS WITH COMMUNITY-ACQUIRED PNEUMONIA}

Community-acquired pneumonia (CAP) is still one of the leading causes of death in the world. The identification of risk factors for poor outcome is crucial to direct empirical antibiotic therapy and supportive measures.

An international database of patients with CAP (CAPO group) reported the outcomes of 118 patients infected with HIV and pneumonia and compared them with 2,790 HIV negative patients with CAP. They observed that the presence of HIV infection did not influence the clinical outcome of hospitalised patients with pneumonia [36]. The delay in diagnosis may have an influence in outcome; SANZ et al. [37] analysed 1,038 cases of CAP and established that an initially less severe clinical presentation was associated with delayed pneumonia diagnosis, and this less severe presentation could be a result of previous treatment with systemic corticosteroids and/or antibiotics. Patients with delayed diagnosis had a higher probability of suppurative complications.

The utility of biomarkers in CAP has been extensively studied. The German CAPNETZ network reported a series of biomarkers; among them, pro-adrenomedullin was the biomarker with the best performance, and added significantly to CRB-65 score for prediction of short- and long-term mortality risk in patients admitted for pneumonia [38]. Another recent report indicated that procalcitonin (PCT) was helpful in predicting adverse events, and moderately improved the predictions of mortality in higher risk classes according to pneumonia severity index (PSI) and CURB-65 scores [39]. Of importance, the medications administered to patients with severe CAP may influence the serum levels of biomarkers and decrease their prognostic value. SNIJDERS et al. [40] observed in a population of 176 patients admitted for CAP that the use of prednisolone had a marked influence on C-reactive protein (CRP) decline, but not on PCT.

Another report from the CAPO group indicated that patients with CAP and controlled diabetes mellitus do not have worse outcomes compared with patients without diabetes [41]; however, obesity, particularly in males, was associated in another series with higher risk of hospitalisation for CAP, explained, at least in part, by the occurrence of other chronic diseases [42].

In recent years, it has been suggested that healthcare-associated pneumonia (HCAP) be established as an additional type of pneumonia. POLVERINO et al. [43] described clinical features and biomarkers of a series of 75 cases meeting HCAP criteria. These patients had frequent comorbidities and increased levels of serum inflammatory markers, which parallels the observed increased risk of poor outcomes compared with CAP. 


\section{NEW ASPECTS OF TREATMENT OF PATIENTS WITH LOWER RESPIRATORY TRACT INFECTIONS}

There are unmet needs in the treatment of respiratory infections. Increasing rates of resistance to the usual antibiotics and the need to prevent acute episodes in individuals colonised with bacteria in the lower airways are challenges that have to be faced in clinical practice. The prudent use of antibiotics in respiratory infections is necessary, and clear guidance on when and how to use antimicrobials must be developed [44]. WANG et al. [45] presented results of a randomised, double-blind, placebocontrolled trial of Antiwei, a traditional Chinese herb for the treatment of influenza A. The authors observed a reduction in the severity of symptoms and a significant increase in patient recovery, which merits further studies. The development of specific monoclonal antibodies will help to overcome the problem of bacterial resistance. Panobacumab is a human monoclonal antibody which is directed against Pseudomonas aeruginosa serotype $\mathrm{O} 11$ and provided promising results in the treatment of a small group of patients with ventilator-associated pneumonia caused by Pseudomonas in a pilot study [46].

The treatment of complications or comorbidities in patients with severe pneumonia is also an important strategy to improve outcomes. MORTENSEN et al. [47] conducted a cohort study in 50,119 patients older than 65 yrs admitted for pneumonia in the USA and observed that prior use of statins was associated with decreased occurrence of serious cardiac arrhythmia in this population.

MATKOVIC et al. [48] reported data from Croatia on the implementation of switch therapy in patients admitted for community-acquired pneumonia. Their results showed that despite guidelines, the switch therapy was performed significantly later than recommended, which caused significant unnecessary costs.

\section{CHRONIC BRONCHIAL INFECTION IN PATIENTS WITH COPD AND BRONCHIECTASIS}

Treatment of chronic bronchial infection in patients with bronchiectasis is not clearly established. The use of antibiotics delivered by inhalation is an alternative due to the high concentrations of the drug achieved in the site of infection. The new liposomal formulation of inhaled ciprofloxacin has been tested in patients with bronchiectasis in small studies and demonstrated to be safe and to reduce the $P$. aeruginosa sputum density significantly [49]. Another strategy would be the use of long-term oral therapy with macrolides. DWARAKANATH et al. [50] reported results of the use of azithromycin at dosing schedule of $500 \mathrm{mg}$ once daily for 6 days, $250 \mathrm{mg}$ once daily for 6 days and $250 \mathrm{mg}$ thrice weekly in patients with bronchiectasis. Their results showed a reduction in sputum volume and colour, in cough frequency and in infective exacerbations, suggesting that azithromycin may play a role in long-term management of this condition.

Azithromycin has also been evaluated also in the treatment of patients with COPD. In a double-blind, placebo-controlled study using azithromycin $500 \mathrm{mg}$ once daily for 3 days every month over 36 months in a group of 575 patients, the authors reported a significant reduction in days with exacerbation compared to placebo, but no difference in terms of pulmonary function, quality of life or mortality [51].

\section{AETIOLOGY AND OUTCOMES OF INFECTIVE EXACERBATIONS OF COPD}

The main cause of death in COPD is exacerbations of the disease. The aetiology of these episodes may be difficult to elucidate, with respiratory infections being responsible for the majority of cases. In a multicentre study, CosIO et al. [52] found two or more bacteria in $50 \%$ of sputum samples of patients admitted for an exacerbation of COPD by using PCR technique in sputum supernatants; moreover, only $5 \%$ of patients showed no micro-organism both in sputum culture and PCR. The role of viruses as triggers of exacerbations has been elegantly described by works of MALLIA co-workers [53, 54] using a novel human model of COPD exacerbation with experimental rhinovirus infection. This infection induces high airway levels of neutrophil elastase that correlate with clinical outcomes, demonstrating the decisive role of viruses as inducers of exacerbations [53]. By using the same model, the authors were able to demonstrate that viral infections may be a mechanism of increased pulmonary T-cells in COPD, thus initiating an inflammatory cascade in the airways [54]. The new diagnostic techniques allow a better detection rates of viruses in patients with COPD, a French study using real time PCR microarray detection methods in 53 exacerbations in 26 patients identified viruses in $43 \%$ of cases, and human metapneumovirus and human rhinovirus infection were detected in $15 \%$ and $21 \%$ cases, respectively [55], which supports again the high frequency of viral infection as trigger of exacerbations in COPD.

Haemophilus influenzae is the bacterial species most frequently found in bronchial secretions, both in stable and in exacerbated patients with COPD, but the mechanisms of persistence of Haemophilus in the bronchial epithelium are largely unknown. MiLlares et al. [56] demonstrated that patients colonised with Haemophilus presented a decreased immune response (immunoglobulin A) against these micro-organisms, which could be a facilitating factor for colonisation. It has been demonstrated that patients colonised, even after a course of eradicating antibiotics, will be re-colonised again in a period of a few weeks [57], thus suggesting that these facilitating factors may persist in patients with COPD.

One of the areas of more intense research in the field of exacerbations of COPD is the search for markers of bacterial infection during an exacerbation. Results derived from a randomised clinical trial with antibiotics in exacerbated patients with COPD have shown that CRP was superior to PCT as a marker for bacterial presence and might be a valuable tool to select patients for antibiotic therapy, although is difficult to establish a cut-off point for the decision to treat with antibiotics in an individual patient [58].

Medication administered for stable COPD may have an impact on the outcome of exacerbations. The role of inhaled corticosteroids as risk factors for the development of pneumonia has been described in long-term studies in patients with COPD; however, the same studies did not describe an increase in mortality associated with pneumonia [59]. In a large group of patients with COPD admitted for pneumonia, it was observed that the chronic use of inhaled corticosteroids had no impact on severity or outcome, after adjustment for COPD severity and variables included in the PSI [60].

\section{CONCLUSIONS}

As in the previous congresses in Vienna and Berlin, resistant forms of active $\mathrm{TB}$ and new diagnostics for $\mathrm{TB}$ infection 
continued to be hot topics also during the 20th ERS Congress in Barcelona.

New alarming reports emphasised the threat posed by MDR/ $\mathrm{XDR}-\mathrm{TB}$ in Eastern European and former Soviet Union countries, highlighting the changing pattern of distribution of resistant forms, especially among new cases. Conversely, new tools have been validated to survey these forms and there is hope that their implementation will improve early diagnosis, infection control and clinical management of MDR/XDR-TB. Cross-sectional reports have been presented about the value of IGRAs in several cohorts of patients: two systematic reviews / meta-analysis on the role of IGRAs in clinical practice led to the conclusions that blood tests are not sufficiently accurate to be used as rule-out tests for active TB, and that they may present operational advantages compared with the TST for the diagnosis of LTBI, especially among groups with high rates of falsepositive TST results; their role in high-risk groups, such as children and immunocompromised patients, is still debated and longitudinal data from properly designed studies are still awaited.

Fortunately, lower respiratory infections including pneumonia are nowadays an area of intense research that has produced advances that hopefully are reflected in the better care of our patients. Much has been learnt as regards the role of viruses in COPD exacerbations, including the clinical and epidemiological implications of the new influenza A virus, as well as the underlying evidence for Haemophilus influenzae as the most important bacterial pathogen in stable and exacerbated patients. Macrolides carry considerable potential in the prevention of exacerbations in patients with bronchiectasis but also in those with COPD. Important data have been contributed supporting the predictive potential of biomarkers, such as PCT and adrenomedullin, and indicating that they might refine clinical prediction rules.

\section{STATEMENT OF INTEREST}

None declared.

\section{ACKNOWLEDGEMENTS}

The author's affiliations are: M. Miravitlles, Institut d'Investigacions Biomédiques August Pi i Sunyer (IDIBAPS), Hospital Clínic, CIBER de Enfermedades Respiratorias (CIBERES), Barcelona, Spain; G. Sotgiu, Hygiene and Preventive Medicine Institute, University of Sassari, Sassari, Italy; G. Dimopoulos, 2nd Department of Critical Care, Medical School, University of Athens, University Hospital Attikon, Athens, Greece; G. Rohde, Dept of Respiratory Medicine, Maastricht University Medical Center, Maastricht, The Netherlands; R. Centis, WHO Collaborating Centre for Tuberculosis and Lung Diseases, Fondazione S. Maugeri, Care and Research Institute, Tradate, Italy; G. Ferrara, Section of Respiratory Diseases, Dept of Internal Medicine, S Maria Hospital, University of Perugia, Terni, Italy; S. Ewig, Thoraxzentrum Ruhrgebiet, Kliniken für Pneumologie und Infektiologie, EVK Herne and Augusta-KrankenAnstalt Bochum, Germany; F. Blasi, Respiratory Medicine Section, Dipartimento Toraco-Polmonare e Cardiocircolatorio, University of Milan, IRCCS Fondazione Cà Granda Milan, Italy; G.B. Migliori, WHO Collaborating Centre for Tuberculosis and Lung Diseases, Fondazione S. Maugeri, Care and Research Institute, Tradate, Italy.

\section{REFERENCES}

1 Miravitlles M, Ferrara G, Lange C, et al. TB or not TB: update from the ERS Respiratory Infection Assembly 10. Eur Respir J 2010; 36: $665-670$.
2 Woodhead M, Blasi F, Ewig S, et al. Guidelines for the management of adult lower respiratory tract infections. Eur Respir J 2005; 26: $1138-1180$.

3 Migliori GB, Besozzi G, Girardi E, et al. SMIRA/TBNET Study Group. Clinical and operational value of the extensively drugresistant tuberculosis definition. Eur Respir J 2007; 30: 623-626.

4 Migliori GB, Sotgiu G, Lange C, et al. Extensively drug-resistant tuberculosis: back to the future. Eur Respir J 2010; 36: 475-477.

5 Sotgiu G, Ferrara G, Matteelli A, et al. Epidemiology and clinical management of XDR-TB: a systematic review by TBNET. Eur Respir J 2009; 33: 871-881.

6 Lange C, Yew WW, Migliori GB, et al. The European Respiratory Journal targets tuberculosis. Eur Respir J 2010; 36: 714-715.

7 Raviglione MC, Lange C, Migliori GB. Preventing and managing antimicrobial resistance: imperative for chest physicians. Eur Respir J 2011; 37: 978-981.

8 Siafakas NM, Decramer M, Rabe KF. 2010: the Year of the Lung. Eur Respir J 2011; 37: 1-2.

9 Eickelberg O, Laurent G, Nicod LP, et al. European Respiratory Society MD PhD programme in respiratory science. Eur Respir J 2010; 36: 229-230.

10 Genomics to combat Resistance against Antibiotics in Communityacquired LRTI in Europe. www.grace-lrti.org Date last updated: March 1, 2011. Date last accessed: March 1, 2011.

11 European network for study and clinical management of TB drug resistance. www.tbpannet.eu Date last updated: March 1, 2011 Date last accessed: March 1, 2011.

12 Story A, Hemming S, Yates S, et al. Tackling tuberculosis among hard to reach groups in London - the Find \& Treat experience. Eur Respir J 2010; 36: Suppl. 54, 984s.

13 Kruijshaar ME, Abubakar I, Crofts J, et al. Tuberculosis in London and in other English urban areas. Eur Respir J 2010; 36: Suppl. 54, $985 \mathrm{~s}$.

14 Anderson L, Tamne S, Droboniewski F, et al. Factors preventing better treatment completion among MDRTB cases in a richresource setting. Eur Respir J 2010; 36: Suppl. 54, 346s.

15 Mishustin S, Golubchikov P, Barnashov A, et al. Success of the Tomsk Oblast tuberculosis control program for 2004-2009, the Global Fund grant. Eur Respir J 2010; 36: Suppl. 54, 985s.

16 Crudu V, Blagodeteleva G, Golisceva O, et al. High prevalence of drug-resistant tuberculosis in Republic of Moldova, 1995-2009. Eur Respir J 2010; 36: Suppl. 54, 919s.

17 Malic A, Stratan E, Crudu V, et al. Rapid genotypic assays for detection the rifampin and isoniazid resistance in $M$. tuberculosis strains and clinical specimens in Moldova. Eur Respir J 2010; 36: Suppl. 54, 345s.

18 Sotgiu G, Centis R, D'Ambrosio L, et al. TBNET Tubeculosis Network European Trialsgroup. Development of a standardized tool to survey MDR-/XDR-TB case management in Europe. Eur Respir J 2010; 36: Suppl. 54, 32s.

19 Facchini A, D'Ambrosio L, Sotgiu G, et al. TBNET Tuberculosis Network European Trialsgroup. Is management of MDR-/XDRTB in Europe adequate? A TBNET survey. Eur Respir J 2010; 36: Suppl. 54, 32s.

20 Sotgiu G, Centis R, D'ambrosio L, et al. TBNET MDR-TB project. Development of a standardised tool to survey MDR-/XDR-TB case management in Europe. Eur Respir J 2010; 36: 208-211.

21 Sotgiu G, D'Ambrosio L, Centis R, et al. TB and M/XDR-TB infection control in European TB reference centres: the Achilles's heel? Eur Respir J 2011; (in press).

22 Pele I, Lihatchi L, Tudose C, et al. Tuberculosis (TB) and HIV coinfection in Romania. Eur Respir J 2010; 36: Suppl. 54, 690s.

23 Shean K, Badri M, Symons G, et al. Adverse drug reactions in South African patients being treated for XDR-TB. Eur Respir J 2010; 36: Suppl. 54, 33s.

24 Sester M, Sotgiu G, Girardi E, et al. Evidence assessment on the use of IGRA testing in diagnosing active tuberculosis: A systematic TBNET review. Eur Respir J 2010; 36: Suppl. 54, 370s. 
25 Sester M, Sotgiu G, Lange C, et al. Interferon- $\gamma$ release assays for the diagnosis of active tuberculosis: a systematic review and metaanalysis. Eur Respir J 2011; 37: 100-111.

26 Diel R, Cirillo D, Ferrara G, et al. Evidence assessment on the use of IGRA testing in diagnosing latent tuberculosis - a TBNET review. Eur Respir J 2010; 36: Suppl. 54, 370s.

27 Diel R, Goletti D, Ferrara G, et al. Interferon- $\gamma$ release assays for the diagnosis of latent Mycobacterium tuberculosis infection: a systematic review and meta-analysis. Eur Respir J 2011; 37: 88-99.

28 Sester M, van Leth F, Girardi E, et al. Head-to-head analysis of IGRAs and skin-testing in immunocompromised patients: Interim analysis of a multicenter TBNET study. Eur Respir J 2010; 36: Suppl. 54, 370s-371s.

29 Ruhwald M, Belard E, Semb S, et al. Effects of corticosteroid treatment on the performance of QuantiFERON Gold In-Tube test in the diagnosis of latent tuberculosis infection. Eur Respir J 2010; 36: Suppl. 54, 23s.

30 Socaci A, Tudorache V, Nini G. Performance of the tuberculin skin test and interferon- $\gamma$ release assays for detection of tuberculosis infection in immunocompromised patients in a TB endemic population. Eur Respir J 2010; 36: Suppl. 54, 23s.

31 Patel AS, Stokes J, Shah M, et al. The use of IGRA in investigating latent TB - a UK survey. Eur Respir J 2010; 36: Suppl. 54, 371s.

32 Schablon A, Diel R, Ringshausen F, et al. Serial testing with the interferon- $\gamma$ release assay in German healthcare workers. Eur Respir J 2010; 36: Suppl. 54, 22s.

33 Torres Costa J, Silva R, Sá R, et al. Serial testing with the interferon- $\gamma$ release assay in Portuguese healthcare workers. Eur Respir J 2010; 36: Suppl. 54, 22s-23s.

34 James P, Christopher DJ, Premkumar B, et al. Serial testing for tuberculosis infection in a cohort of Indian nursing students: QFT conversions and reversions. Eur Respir J 2010; 36: Suppl. 54, 21s-22s.

35 Chee C, KhinMar KW, Gan SH, et al. Repeat testing of ELISpotpositive TB contacts at 32 to 36 months post-exposure. Eur Respir J 2010; 36: Suppl. 54, 22s.

36 Peyrani $\mathrm{P}$, Bordon J, Ayesu $\mathrm{K}$, et al. CAPO Investigators. Clinical outcomes of HIV-infected patients hospitalized with communityacquired pneumonia: results from CAPO international cohort study. Eur Respir J 2010; 36: Suppl. 54, 617s.

37 Sanz F, Fernández E, Cervera A, et al. Clinical factors associated with delayed diagnosis in hospitalized community-acquired pneumonia (CAP). Impact on outcome. Eur Respir J 2010; 36: Suppl. 54,617s.

38 Krüger S, Ewig S, Giersdorf S, et al. Prohormones of adrenomedullin, atrial natriuretic peptide, vasopressin and endothelin to predict short- and long-term survival in community-acquired pneumonia - Results from the German competenze network (CAPNETZ). Eur Respir J 2010; 36: Suppl. 54, 617s.

39 Schuetz P, Suter-Widmer I, Chaudri A, et al. Prognostic value of procalcitonin in community-acquired pneumonia. Eur Respir $J$ 2011; 37: 384-392.

40 Snijders D, de Graaff CS, van der Werff TS, et al. The influence of prednisolone on C-reactive protein and procalcitonin in patients hospitalized with community-acquired pneumonia. Eur Respir J 2010; 36: Suppl. 54, 617s-618s.

41 Jimenez P, Fernandez P, Peyrani P, et al. CAPO Investigators. The presence of diabetes mellitus does not influence clinical outcomes in patients with community-acquired pneumonia: results from the CAPO international cohort study. Eur Respir J 2010; 36: Suppl. 54, 618s.
42 Kornum JB, Norgaard M, Dethlefsen C, et al. Obesity and risk of subsequent hospitalization with pneumonia. Eur Respir J 2010; 36: 1330-1336.

43 Polverino E, Cilloniz C, Esquinas C, et al. Healthcare-associated pneumonia (HCAP): clinical features and biomarkers. Eur Respir J 2010; 36: Suppl. 54, 618s.

44 Rohde GG. Prudent use of antibiotics: acute exacerbation of COPD as an example. Eur Respir J 2010; 36: 983-985.

45 Wang L, Zhang RM, Liu GY, et al. Chinese herbs in treatment of influenza A: a multi-centre, randomized, double-blind, placebocontrolled trial. Eur Respir J 2010; 36: Suppl. 54, 1018s.

46 Tamm M, Lu Q, Dugard A, et al. Panobacumab, a fully human monoclonal antibody for ventilator associated pneumonia caused by Pseudomonas aeruginosa. Eur Respir J 2010; 36: Suppl. 54, 1017s.

47 Mortensen E, Copeland L, Restrepo M, et al. Impact of prior statin use on cardiac arrhythmias for patients hospitalized with pneumonia. Eur Respir J 2010; 36: Suppl. 54, 1017s.

48 Matkovic Z, Piskac-Zivkovic N, Tudoric N. Switch from intravenous to oral antibiotic therapy in hospitalized patients with nonsevere community-acquired pneumonia. Eur Respir J 2010; 36: Suppl. 54, 1018s.

49 Bruinenberg P, Serisier D, Blanchard J, et al. Effects and modulation of release rate of inhaled ciprofloxacin with liposomal formulations in healthy subjects and patients with bronchiectasis. Eur Respir J 2010; 36: Suppl. 54, 1017s.

50 Dwarakanath A, Nanjappa J, Taylor C, et al. Effects of long term low dose azithromycin in patients with non-cystic fibrosis bronchiectasis. Eur Respir J 2010; 36: Suppl. 54, 1017s-1018s.

51 Mygind LH, Pedersen C, Vestbo J, et al. A randomized, placebocontrolled 3 years study of prophylactic azithromycin in 575 patients with chronic obstructive pulmonary disease (COPD). Eur Respir J 2010; 36: Suppl. 54, 1018s.

52 Cosio BG, García-Nuñez M, Monsó E, et al. Microbiology of COPD exacerbations at hospital admission: the ECOS study. Eur Respir J 2010; 36: Suppl. 54, 684s.

53 Mallia $\mathrm{P}$, Message S, Contoli M, et al. Sputum neutrophil elastase in viru-induced COPD exacerbations correlate with clinical outcomes and virus load. Eur Respir J 2010; 36: Suppl. 54, 685s.

54 Mallia $\mathrm{P}$, Message S, Contoli M, et al. Rhinovirus infection induces increases in CD3+ and CD8+ T cells in BAL in COPD patients. Eur Respir J 2010; 36: Suppl. 54, 686s.

55 Perotin JM, Andreoletti L, Deslee G, et al. RT-PCR microarray detection of viral respiratory pathogens demonstrateds the major role of human metapneumovirus and human rhinovirus in acute exacerbations of COPD in France. Eur Respir J 2010; 36: Suppl. 54, 686s.

56 Millares L, Marín A, García-Aymerich J, et al. Specific immune response against Haemophilus influenzae in stable COPD. Eur Respir J 2010; 36: 685s.

57 Miravitlles M, Marín A, Monsó E, et al. Efficacy of moxifloxacin in the treatment of bronchial colonization in COPD. Eur Respir J 2009; 34: 1066-1071.

58 Daniels J, Snijders D, Lutter R, et al. Procalcitonin versus C-reactive protein in the management of severe acute exacerbations of COPD. Eur Respir J 2010; 36: Suppl. 54, 685s.

59 Crim C, Calverley PMA, Anderson JA, et al. Pneumonia risk in COPD patients receiving inhaled corticosteroids alone or in combination: TORCH study results. Eur Respir J 2009; 34: 641-647.

60 Singanayagam A, Akram A, Chalmers J, et al. Impact of inhaled corticosteroid use on outcome in COPD patients hospitalized with pneumonia. Eur Respir J 2010; 36: Suppl. 54, 685s. 